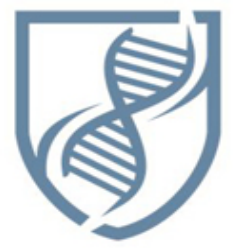

Journal of Bioscience and Applied Research
JBAAR

WWW.JBAAR.ORG

\title{
Ameliorating effect of propolis and moringa extract against equigan induced neurotoxicity and oxidative stress on rat hippocampus
}

\author{
Ehab Tousson, Ezar Hafez, Ahmed Massoud and Ahmed A. Elfeky \\ Zoology Department, Faculty of Science, Tanta University, Tanta 31527, Egypt \\ Corresponding author e.mail. toussonehab@yahoo.com-
}

\begin{abstract}
In most countries worldwide, Equigan is anabolic steroid that is forbidden for human uses or for meat production. The present study was designed to investigate the ameliorating role of Propolis and moringa leaf extract (MLE) against Equigan induced neurotoxicity and oxidative stress on rat hippocampus. A total of 48 healthy male albino rats weighing 170-200 g and of 10-12 weeks age were divided into 6 groups ( 8 animals each). $1^{\text {st }}$ Control group includes animals that injected intramuscularly with olive oil for 12 weeks. $2^{\text {nd }}$ and $3^{\text {rd }}$ groups were rats received Propolis and MLE respectively. $4^{\text {th }}$ experimental group include animals that receive intramuscular injections of Equigan for 12 weeks; $5^{\text {th }}$ and $6^{\text {th }}$ groups where rats intramuscular injected with Equigan and treated with Propolis and MLE at the same time respectively. The obtained results indicate that hippocampal nitric oxide (NO), malondialdehyde (MDA), acetylcholine esterase (AChE) and total protein were significantly increased in Equigan group when compared with control group. In contrast hippocampal catalase, SOD and total thiol levels were significantly decreased in Equigan group when compared with control group. On the other hand hippocampal NO, MDA, ACE and total protein in Equigan group were significantly increased when compared with co-treated Equigan with MLE or Propolis groups. In contrast; hippocampal catalase, SOD and total thiol levels were significantly decreased in Equigan group when compared with co-treated Equigan with MLE or propolis groups. We can concluded that; MLE and propolis extract ameliorate the neurotoxicity and oxidative stress on rat hippocampus induces by Equigan.
\end{abstract}

Keywords: Steroid hormones; Equigan; Moringa oleifera; Propolis; Hippocampus; Oxidative stress.

\section{Introduction}

Anabolic and androgenic steroids are synthetic substances related to the primary male sex hormone, testosterone. Their biological actions include anabolic effect promoting muscle growth, behavioral effect causing aggressiveness among others, and hematopoietic effect. Because of their musclebuilding and growth-enhancing properties, steroid hormones are still illegally administered to foodproducing animals (Gabr et al., 2009; Verheyden et al., 2010; Tousson et al., 2013). Equigan (Boldenone; 1, 4-androstadiene-17-ol-3-one) is an anabolic androgenic synthetic commercial steroid and is well known under the trade names Equipoise, Ganabol and Ultragan (Sullivan et al., 1998; Soma et al., 2007; Arioli et al., 2012). Anabolic androgenic steroids caused many adverse effects as disturbance of the endocrine and immune function (Sullivan et al., 1998; Pey et al., 2003).

Hippocampus is a part of the forebrain, located in the medial temporal lobe. It is critical for the formation of those kinds of memories, which can be consciously declared. Due to its self-generated network patterns, newly acquired memories are gradually transferred to neocortical stores through the process of memory consolidation. In Alzheimer's disease, the hippocampus is one of the first regions of the brain to suffer damage; memory problems and disorientation appear among the first symptoms (Zhu et al., 2007).

The hippocampus, as the brain's search engine also allows a fast and efficient search among the deposited memories in the neocortex, which is a 
process essential for planning the future and generating creative ideas.

Propolis is a resinous substance collected, transformed and used by bees to seal holes in their honeycombs, smooth out the internal walls. Honeybees (Apis mellifera L.) collect the resin from tree bark and leaf buds. Propolis also contains more than 300 biochemical constituents, including mostly a mixture of polyphenols, flavonoidaglycones, phenolic acid and their esters, and phenolic aldehydesand ketones, terpenes, sterols, vitamins, amino acids. In addition, Propolis possesses several biological properties such as antiinflammatory, anticancer, antioxidant, antibiotic and antifungal activities (Banskota et al., 2001).

Moringa oliefiara, an edible tree, almost all parts of the plant have been utilized in traditional medicine properties (Rathi et al., 2006; Shenton et al., 2012). Moringa oleifera has antioxidant activity. The extract of Moringa oleifera leaf (MLE) also has strong antiradical activity; phenolic acids (derivatives of caffeic, p-coumaric and ferulic acids) are the dominant phenolic constituents of MLE (Atawodi et al., 2010). The medicinal properties derive from high concentrations of phytochemicals found in all parts of the crop (Foidl et al., 2001; King et al., 2009).

Equigan has dual effects on humans, both directly and indirectly; directly as injection to build muscles and indirectly as through consuming meat of animals that were treated with Equigan (Tousson et al., 2013). However, the action of these steroids on the structure and function of hippocampus still unclear, therefore, the aim of the present study was to investigate the possible prophylactic effect of GLE and Propolis on the neurotoxicity of the rat hippocampus by Equigan.

\section{Materials and Methods}

\section{Experimental animals \& study design}

48 healthy male albino rats weighing 170-200 g and of 1012 weeks age, supplied from the animal house of National Research Center (Dokki, Giza, Egypt) were used for this study. The animals had free access to water. The experiment continued for 12 weeks on which constant weight of diet was given for each rat. "All authors hereby declare that "Principles of laboratory animal care" (NIH publication No. 85-23, revised 1985) were followed, as well as specific national laws where applicable. All experiments have been examined and approved by the appropriate ethics committee"

Animals were divided into 6 groups (8 animals each). G1 is control group includes animals that injected intramuscularly with olive oil for 12 weeks. G2 and G3 were rats that receive MLE (orally, $200 \mathrm{mg} / \mathrm{kg}$ body weight) and Propolis (intragastrically, 50mg/kg body weight) water extract respectively. G4 includes animals that receive intramuscular injections of Equigan $(5 \mathrm{mg} / \mathrm{Kg}$ body weight) for 12 weeks. G5 and G6 where rats intramuscular injected with Equigan and treated with MLE and Propolis at the same time respectively.

At the end of the experiment, the animals were fasted for 10 hours and then euthanized with intraperitoneal injection of sodium pentobarbital $(0.2 \mathrm{ml} / \mathrm{Kg})$ and subjected to a complete necropsy. Blood samples were individually collected from the inferior vena cava of each rat in non heparinized glass tubes. Blood serum was separated by centrifugation at $3000 \mathrm{rpm}$ for 15 minutes. The collected serum was stored at $-18{ }^{\circ} \mathrm{C}$.

\subsection{Histological investigation}

The skulls were opened with fine scissors and the brains were excised and fixed in $4 \%$ paraformaldhyde in phosphate buffered saline $(0.1 \mathrm{M}, \mathrm{Ph} 7.4 \mathrm{PBS})$ for 24 hours at $4^{\circ} \mathrm{C}$. Fixed brains were dehydrated through a graded series of ethanol and embedded in paraffin according to standard procedures. Paraffin sections $(5 \mathrm{~m}$ thick) were mounted on gelatin chromalum-coated glass slides and used for Haematoxylin and eosin stains as a routine method (Bancroft and Stevens, 1990). All stained slides were viewed using Olympus microscope and images were captured by a digital camera (Cannon 620). Brightness and contrast were adjusted using Adobe Photoshop software (version 4.0.1; Adobe Systems, Mountain View, California).

\subsection{Homogenate}

$10 \%(\mathrm{~W} / \mathrm{V})$ homogenate of tissue was prepared in ice-cold buffer using chilled glass-teflonproterELvheim, tissue was prepared in grinder tube, then centrifuged at $3000 \mathrm{rpm}$ for $15 \mathrm{~min}$. Determination of hippocampus Malondialdehyde (MDA) level was estimated by a modified method of (Ohkawa et al., 1979) while total thiol of tissues which was determined by the method of Sedlak and Lindsay (1968). Estimation of hippocampus total protein content was determined according to the folinLowry method (Lowry et al., 1951) as modified by (Tsuyosh and James, 1978).

Determination of hippocampus Nitric Oxide Contents (Measured as Nitrate/ Nitrite) by method of (Miranda et al., 2001) was adopted. Estimation of hippocampus acetylcholine esterase (ACE) was estimated using centronic $\mathrm{GMbH}$ kitts according to (Henry et al., 1974). Catalase activity was detected according to the method of Fossati (1984) while super oxide dismutase (SOD) activity was determined according to the method of Nishikimi et al. (1972) . 


\subsection{Statistical Analysis}

Data were expressed as mean values+SEM, and statistical analysis was performed using unpaired $\mathrm{T}$ test to assess the significant differences among the treatment groups. The criterion for statistical significance was set at $\mathrm{P}<0.01$ for the biochemical data. All statistical analyses were performed using SPSS statistical version 16 software package (SPSS Inc, Montreal, Canada).

\section{Results}

The histopathological examination of rat hippocampus sections in control, propolis and MLE groups showed normal architecture as shown in Figures (1-3). Hippocampus sections in rats that treated with Equigan (G4) revealed a large number of degenerating neurons with reduction in the pyramidal cells (Fig. 4) when compared with the control group (Fig. 1). Hippocampus coronal sections in co-treated Equigan with MLE (G5) and with propolis (G6) revealed mild distortion of the pyramidal cells in addition to mild to moderate damages in hippocampal neurons with clear oedema (Figs. 5\&6).

Figures (7-10) showed that hippocampal tNOx, MDA, AChE and total protein were significantly increased in Equigan group (G4) when compared with control (G1), Moringa (G2) and Propolis (G3) groups.

In contrast hippocampal catalase, SOD and total thiol levels were significantly decreased in Equigan group (G4) when compared with control (G1), Moringa (G2) and Propolis (G3) groups (Figures 1113). On the other hand; hippocampal tNOx, MDA, $\mathrm{AChE}$ and total protein were significantly increased in Equigan group (G4) when compared with cotreated MLE (G5) and Propolis (G6) groups (Figures 7 - 10).

In contrast; hippocampal catalase activity, SOD activity and total thiol levels were significantly decreased in Equigan group (G4) when compared with co-treated Equigan with MLE (G5) and Propolis (G6) groups (Figures 11-13). Also hippocampal tNOx, MDA, AChE and catalase activities were significantly increased in co-treated MLE (G5) group when compared with co-treated Equigan with Propolis (G6) group, while SOD activity, total thiol and total protein levels were significantly decreased in co-treated Equigan with MLE (G5) group when compared with co-treated Equigan with Propolis (G6) group (Figures 11-13).
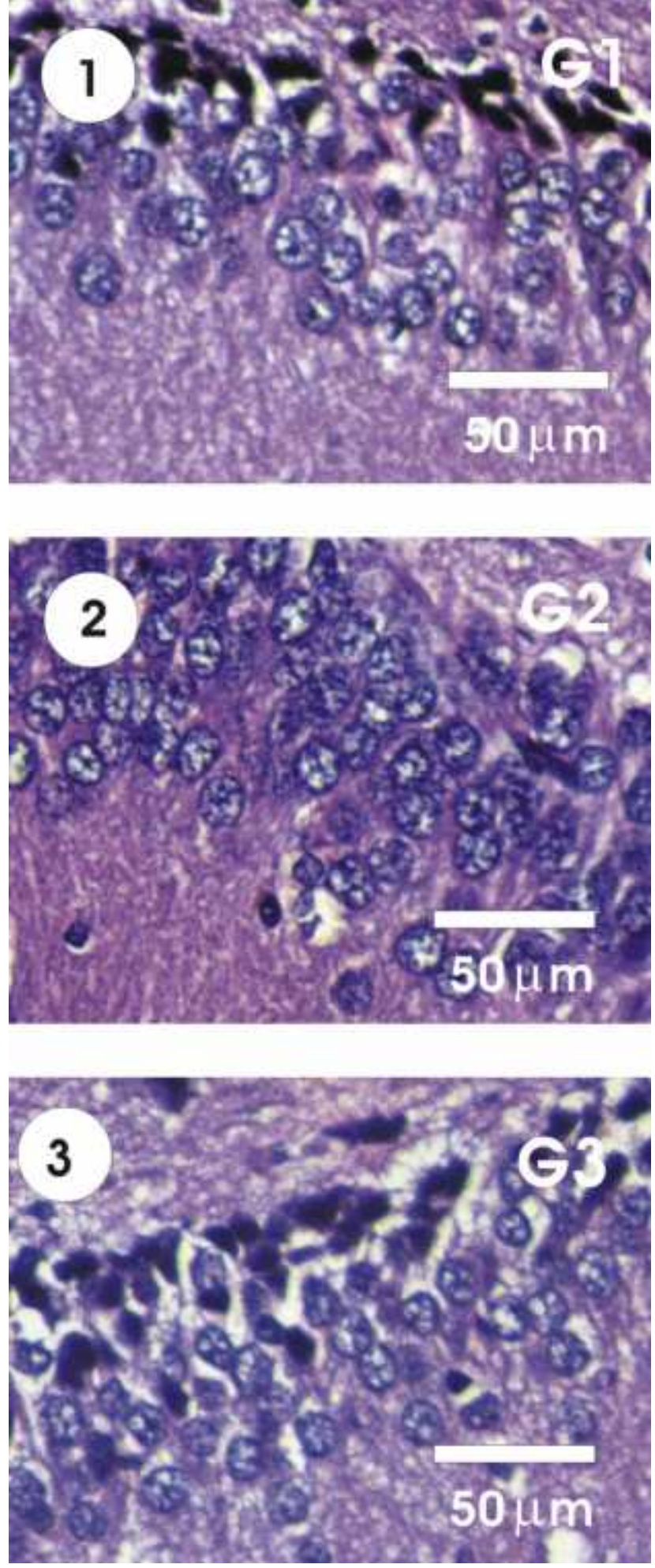

Figures (1-3): Photomicrographs of rat coronal sections (stained by HE) in control (G1), MLE (G2) and Propolis (G3) respectively showing normal structure of hippocampus. 

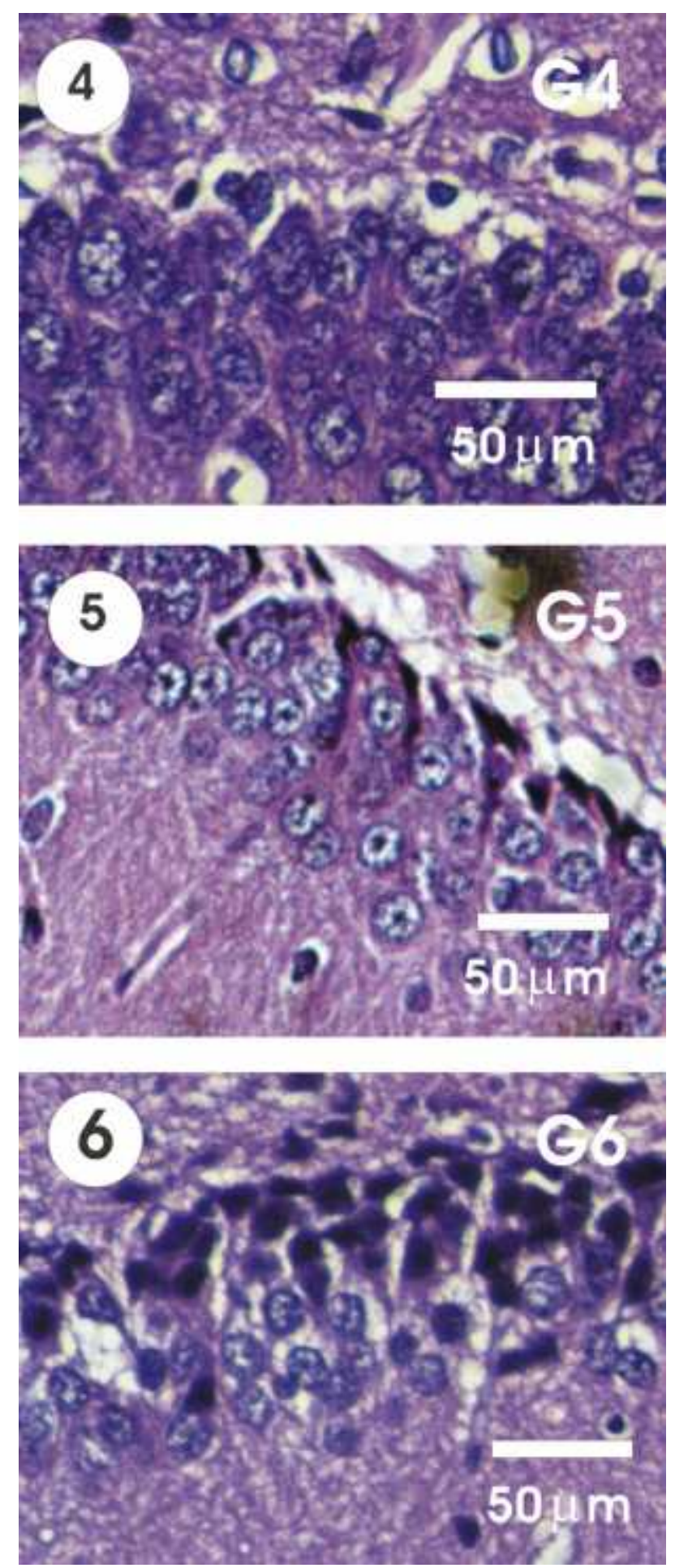

Figures (4-6): 4: Photomicrographs of rat coronal sections (stained by HE). Hippocampus section in Equigan (G4) revealed a marked degenerating neurons with reduction in the pyramidal cells. 5\&6: Hippocampus section in co-treated Equigan with MLE (G5) and with propolis (G6) respectively revealed cytoplasmic vacuolation and mild distortion of the pyramidal cells in addition to mild to moderate damages in hippocampal neurons.

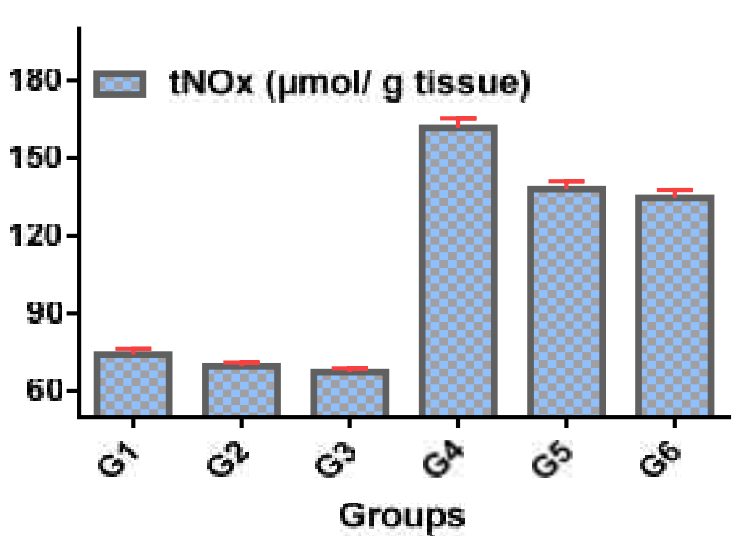

Figure (7): Changes in tNOx levels in experimental groups under study. Where G1, control group; G2, MLE group; G3, propolis group; G4, Equigan group; G5, co-treated Equigan with MLE group; G6, cotreated Equigan with propolis group.

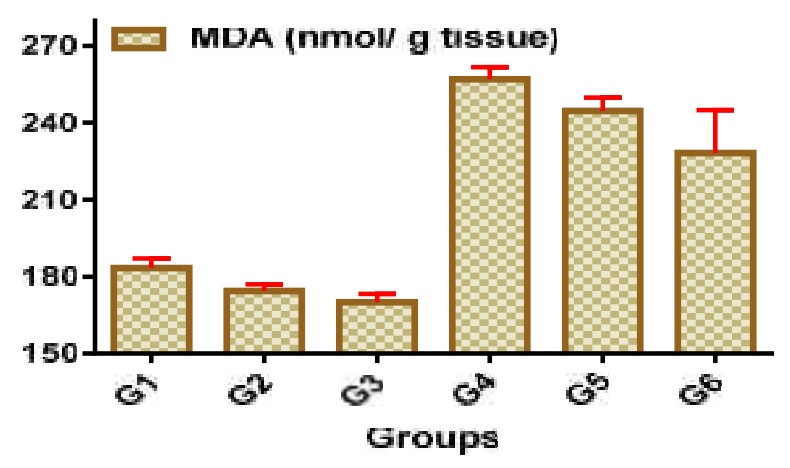

Figure (8): Changes in MDA levels in experimental groups under study. Where G1, control group; G2, MLE group; G3, propolis group; G4, Equigan group; G5, co-treated Equigan with MLE group; G6, cotreated Equigan with propolis group.

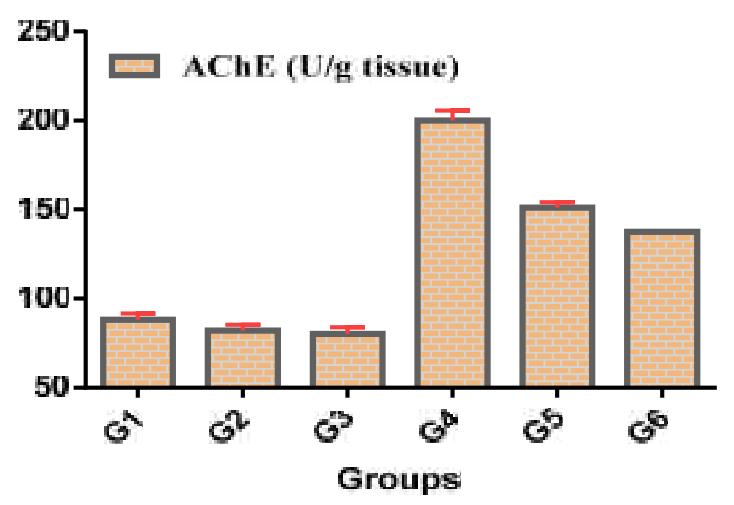

Figure (9): Changes in AChE levels in experimental groups under study. Where G1, control group; G2, 
MLE group; G3, propolis group; G4, Equigan group; G5, co-treated Equigan with MLE group; G6, cotreated Equigan with propolis group.

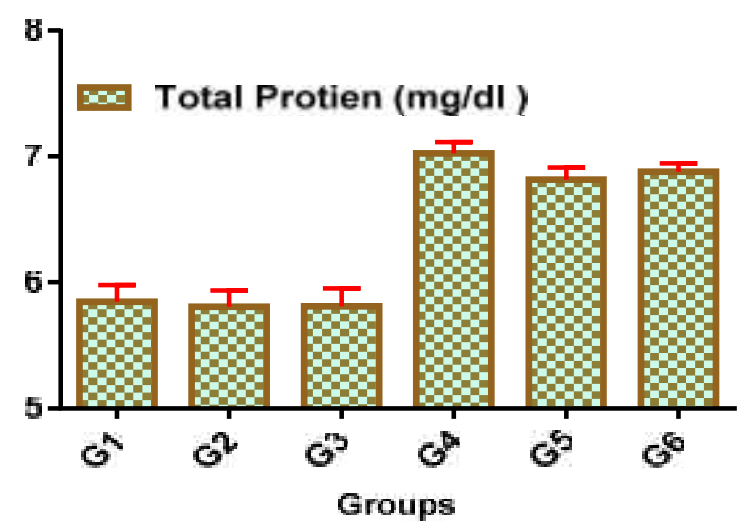

Figure (10): Changes in total protien levels in experimental groups under study. Where G1, control group; G2, MLE group; G3, propolis group; G4, Equigan group; G5, co-treated Equigan with MLE group; G6, co-treated Equigan with propolis group.

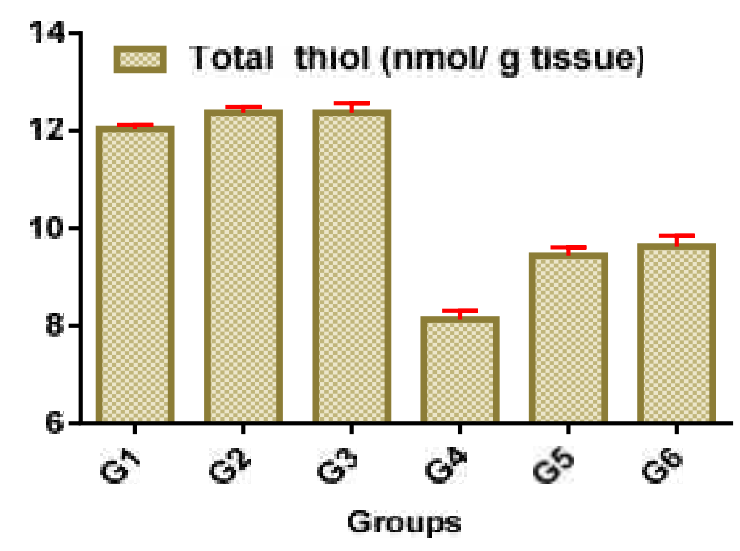

Figure (11): Changes in total thiol levels in experimental groups under study. Where G1, control group; G2, MLE group; G3, propolis group; G4, Equigan group; G5, co-treated Equigan with MLE group; G6, co-treated Equigan with propolis group.

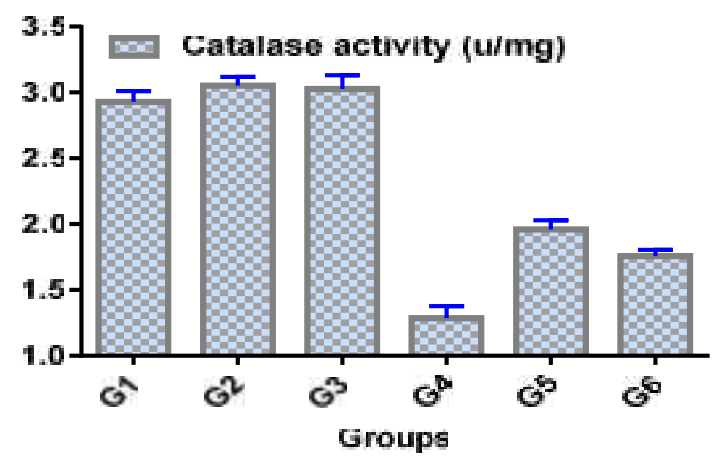

Figure (12): Changes in catalase activity in experimental groups under study. Where G1, control group; G2, MLE group; G3, propolis group; G4, Equigan group; G5, co-treated Equigan with MLE group; G6, co-treated Equigan with propolis group.

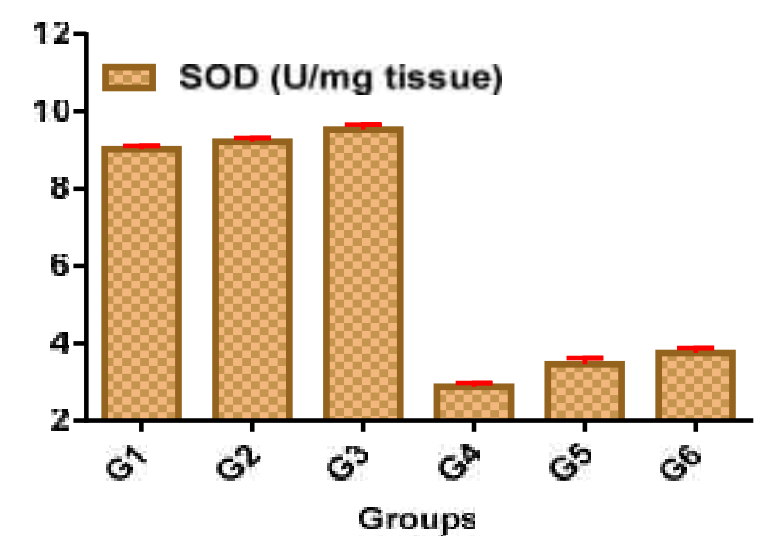

Figure (13): Changes in SOD activity in experimental groups under study. Where G1, control group; G2, MLE group; G3, propolis group; G4, Equigan group; G5, co-treated Equigan with MLE group; G6, co-treated Equigan with propolis group.

\section{Discussion}

Many types of steroids have their own chemical structure. This composition is what causes the variety in the effects you can experience from the different steroids. Being based on testosterone the original androgen which is a hormone that controls the development of male characteristics who ever uses these steroids will be subject, to some extent, to an "androgenic

effect." Their biological actions include anabolic effect promoting muscle growth, behavioral effect causing aggressiveness among others, and hematopoietic effect making them attractive candidates for enhancement of athletic performance (Schänzer, 1996; Pey et al., 2003; Tousson et al., 2011a; 2012a). This study is the first to show the effect of Equigan on the brain tissues in mature animals. Also, the present study was designed to investigate the ameliorating role of Propolis and MLE against Equigan induced neurotoxicity and Oxidative stress on rat hippocampus. The role of Equigan in increasing the muscle size is due to promotion of positive nitrogen balance by stimulating protein production and reducing protein destruction. Our results are in agreement with Moghazy et al. (2012) and Tousson et al. (2012a) who reported that the total protein concentrations in 
male rabbits were significantly increased after boldenone injections.

Antioxidants are molecules that are capable of slowing or preventing the oxidation of other molecules, thereby protecting cells from damages caused by exposure to free radicals, including reactive oxygen species, which are produced during oxidation reactions in biological cells. Antioxidants can be either phytochemicals or vitamins and other nutrients, they range from micro molecules such as glutathione, vitamins, to macromolecules such as catalase, glutathione and peroxidase (Khan et al., 2009; Grigorov, 2012). In the present study, Equigan significantly altered the oxidant/antioxidant balance. In the current study, hippocampal NO, MDA, ACE and total protein were significantly increase in Equigan group when compared with control group. In contrast hippocampal catalase, SOD and total thiol levels were significantly decreased in Equigan group when compared with control group. So, Equigan increased MDA level accompanied with decreased catalase and SOD activities. Similar results were previously reported by other investigators (Grigorov, 2012).

Oxidative stress or oxidative cellular damage with its dual of free radical generation and profound lipid peroxidation are hallmarks of boldenone toxicity (El-Moghazy et al., 2012). Our results are in agreement with Pey et al. (2003) who reported that the anabolic-androgenic steroids induced changes in oxidative stress. Boldenone induces oxidative stress in liver, kidney and muscles tissue as demonstrated by increasing MDA levels (El-Moghazy et al., 2012).

Our results showed that MLE and Propolis has been widely used in activation of the antioxidant enzymes together with the substances that are capable of either reducing reactive oxygen species or preventing their formation, form a powerful reducing buffer, thereby form the protective mechanisms, which maintain the lowest possible levels of reactive oxygen species inside the cell. Our results indicate that rats were received intragastrically with MLE and Propolis have elevated levels of catalase and SOD activity compared with the rats that were intramuscular injected with Equigan only. Gabr et al. (2009) and Tousson et al. (2013) reported that the total protein concentrations in male lambs and rabbits were significantly increased after boldenone injections.
Oxidative stress has been also recently implicated in hormone-induced prostate carcinogenesis (Tam et al., 2003). Catalase activity, SOD activity, and total thiol levels in Equigan group showed significantly decreased $(p<0.01)$ when compared with control group. On the other hand, catalase activity, SOD activity, and total thiol showed increased levels in co-treated Equigan with MLE when compared with Equigan treated group. Propolis is a powerful antioxidant. This effect is due to the high concentration of phenolics and other antioxidant compounds. The radical theory in human physiology claims that the active free radicals are involved in almost all the cellular degradation process and leads to cell death. In the present study, there is significantly increased in the total $\mathrm{NO}_{\mathrm{x}}$ (NO metabolites) in rats that injected with Equigan when compared to control group. This finding may be due to increased vascular oxidative burden associated with homocysteinaemia that induces NADPH oxidase and inducible nitric oxide synthase activity, contributing to increased superoxide radicals production in rat vessels which react with nitric oxide to form peroxynitrite radicals, leading to low NO bioavailability and endothelial dysfunction (Ungvari et al., 2003). Data so far obtained from this study would suggest that administration of MLE and Propolis after Equigan challenge may have beneficial effects that could possibly be ascribed, in part, to its regulation of the oxidant/anti-oxidant balance.

Our results are in agreement with Owusu-Ansah et al. (2011) who reported that MLE contain high total phenolic content and they suggested that the high total phenolic contents are responsible for the corresponding high antioxidant activities of the dried leaf samples of the Moringa accessions and hence support the acclaimed medicinal value of the crop. The obtained results in agreement with Grigorov (2012) who reported that although the human body continuously produces free radicals, it possesses several defense system, which are constitutes of enzymes and radical scavengers such as superoxide dismutase, catalase and glutathione peroxidase while non-enzymatic category contains vitamin $\mathrm{C}, \mathrm{E}, \mathrm{A}, \beta$ caretenoids, uric acid and ubiquinone. Data so far obtained from this study would suggest that administration of Propolis after boldenone challenge may have beneficial effects that could possibly be ascribed, in part, to its regulation of the oxidant/antioxidant balance. So, it is therefore possible that Propolis could scavenge free radicals and produce beneficial effects against Equigan damage in 
hippocampus. This shows that the desired dose of Equigan can safely be used with propolis in improving brain damage in Equigan in male rats.

\section{CONCLUSION}

MLE and propolis extract ameliorate the neurotoxicity and oxidative stress on rat hippocampus induces by Equigan.

\section{COMPETING INTERESTS}

Authors have declared that no competing interests exist.

\section{References}

Atawodi SE, Atawodi JC, Idakwo GA, Pfundstein B, Haubner R, Wurtele G, Spiegelhalder B, Bartsch H, Owen R. (2010). Evaluation of the Polyphenol Content and Antioxidant Properties of Methanol Extracts of the Leaves, Stem And Root Barks Of Moringa Oleifera, Lam. J Med Food, 13(3):710-716.

Bancroft JD, Stevens A. (1990). Theory and Practice of Histological Technique. $3^{\text {rd }}$ Ed. Churchill Livingstone. Edinburgh, London 1990;

Banskota AH, Tezuka Y, Kadota S. Recent progress in pharmacological research of propolis, Phytother Res. 2001; 15: 561-571.

El-Moghazy M, Tousson E, Sakeran M. 2012: Changes in the hepatic and renal structure and function after a growth promoter Boldenone injection in Rabbits. Animal Biol. 62(2): 171-180.

Foidl N, Makkar HPS, Becker K. (2001). The potential of Moringa oleifera for agricultural and industrial uses. In: "The miracle tree," L J Fuglie. 2: $57-$ 66.

Fossati P, Prencipe L, Aebi H, Berti G. 1984: Use of 3,5-dichloro-2-hydroxybenzenesulfonic. Catalase in vitro. Methods Enzymol 105: 121-126.

Gabr F, Abo El-Maaty T, Amal M, Aotifa AM. 2009: Effects of growth promoter Boldenone undecylenate on weaned male lambs. Nature and Science 7(3): 61-69.

Grigorov B. (2012). Reactive oxygen species and their relation to carcinogenesis.Trakia Journal of Sciences 10(3): 83-92.

Henry RF. (1974). Clinical Chemistry Principles and Techniques. 2nd ed. Harper and Row, Hagerstown, 1974.

Khan AA, Jilani G, Akhtar MS, Saqlan M, Rasheed M. (2009). Phosphorus Solubilizing Bacteria: Occurrence, Mechanisms and their Role in Crop Production. J Agric Bio Sci. 1: 48-58.

King AJ, Hel W, Cuevas JA, Ramiaramanana D, Grahaml IA. (2009). Potential of Jatropha curcas as a source of renewable oil and animal feed. Journal of Experimental Botany 10: 2897-2905.
Lowry OH, Rosebrough NJ, Farr AL, Randall RJ. (1951). Protein measurement with Folin phenol reagent. J Biol Chem. 193: 265-275.

Miranda KM, Espey MG, Wink DA. (2001). A rapid, simple spectrophotometric method for simultaneous detection of nitrate and nitrite. Pub MED- indexed for MEDLINE;1: 62-71.

Nishikimi M, Roa NA, Yogi, K. (1972). Measurement of superoxide dismutase. Biochem. Biophys Res Common. 46: 849-854.

Ohkawa H, Ohishi W, Yagi K. (1979). Assay for lipid peroxidation in animal tissues by thiobarbituric acid reaction. Analytical Biochemistry 95: 351-358.

Owusu-Ansah M, Achel DG, Adaboro RM, Asare DK, Amoatey HM. 2011: Total Phenolic Content and Antioxidant Activity in Leaf Samples of Twelve Accessions of Moringa oleifera Lam. Intern J Chem Analytical Sci. 2(10): 1226-1230.

Pey A, Blázquez I, Delgad J, Megıas A. (2003). Effects of prolonged stanozolol treatment on antioxidant enzyme activities, oxidative stress markers, and heat shock protein HSP72 levels in rat liver. J. Steroid Biochem. Molecular Biology 87: 269-277

Rathi B, Bodhankar S, Deheti AM. (2006). Evaluation of aqueous leaves extract of M. oleifera Lin for wound healing in albino rats. Ind J of Exp Bio. 44: 898-901.

Schänzer W. 1996: Metabolism of anabolic androgenic steroids. Clinical Chem. 42: 1001-1020.

Sedlak J, Lindsay RH. (1968). Estimation of total protein-bound, and nonprotein sulfhydryl groups in tissue with Ellman's reagent. Analytical biochemistry 68:90-92.

Shenton ME, Hamoda HM, Schneiderman JS, Bouix S, Pasternak O, Rathi Y. (2012). A review of magnetic resonance imaging and diffusion tensor imaging findings in mild traumatic brain injury. Brain Imaging and Behavior 2: 137-192.

Soma LR, Uboh CE, Guan F, MC-Donnell S, Pack J. (2007).Pharmacokinetics of boldenone and stanozolol and the results of quantification of anabolic and androgenic steroids in race horses and nonrace horses. $\mathbf{J}$ Vet Pharmacol Therap. 30: 101-108.

Sullivan ML, Martinez CM, Gennis P, Gallagher EJ. (1998). The cardiac toxicity of anabolic steroids. Prog Cardiovas. Disc. 41: 1-15

Tam NN, Ghatak S, Ho SM. (2003). Sex hormone-induced alterations in the activities of antioxidant enzymes and lipid peroxidation status in the prostate of Noble rats. Prostate 55: 1-8

Tousson E, Alm-Eldeen A, El-Moghazy M. (2011a). p53 and Bcl-2expression in response to boldenone induced liver cells injury. Toxicology and Industrial Health 27(8): 711-718.

Tousson E, El-Moghazy M, Massoud A, El-Atrash A, Sweef O, Akel A. (2013). Physiological and biochemical changes after boldenone injection in adult rabbits. Toxicology and Industrial Health doi: $10.1177 / 0748233713501365$. 
Tousson E, El-Moghazy M, Massoud A, Akel A. (2012a). Histopathological and immunohistochemical changes in the testis of rabbits after injection with the growth promoter boldenone. Reprod Sci. 19: 253-259.

Tsuyosh O, James KB. (1978). A simplified method of quantitating protein using the biuret and phenol reagents. Anal Biochem. 86: 193- 200.

Verheyden K, Noppe H, Zorn H, Van Immerseel F, Bussche JV, Wille K, Bekaert K, Janssen CR, De Brabander HF, Vanhaecke L. (2010). Endogenous boldenone-formation in cattle: Alternative invertebrate organisms to elucidate the enzymatic pathway and the potential role of edible fungi on cattle's feed. The Journal of Steroid Biochemistry and Molecular Biology, 119: 161-170.

Zhu CL, Zheng Y, Jia Y. (2007). A theoretical study on activation of transcription factor modulated by intracellular $\mathrm{Ca}^{2+}$ oscillations. Biophys Chem. 129(1): 4955. 